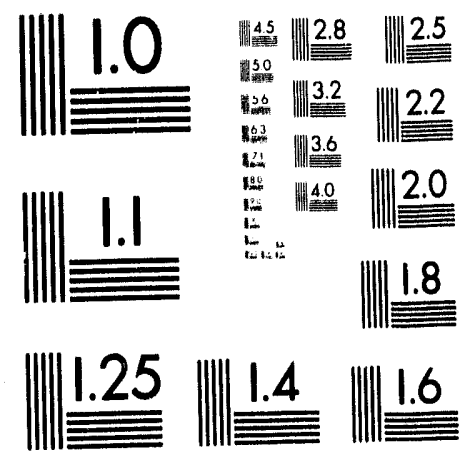



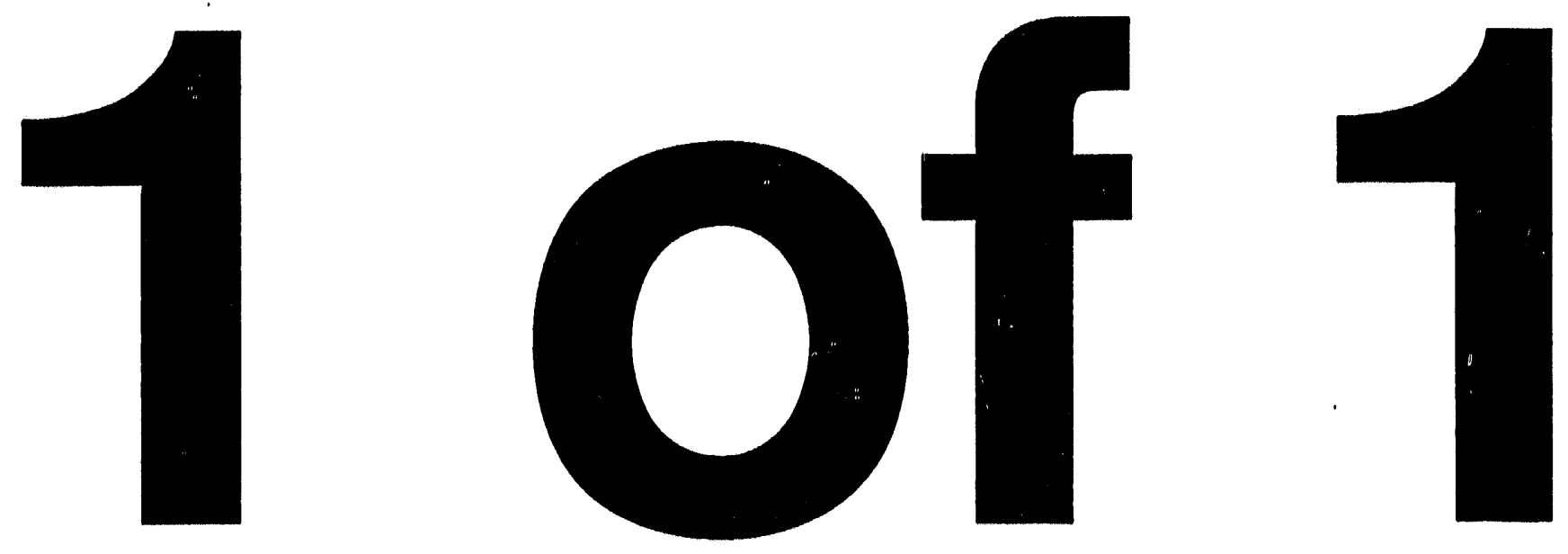
TITLE: Prototype Tests and Description of a 60 Telsa QuasiContinuous Magnet

AUTHOR(S): T. Dominguez, T.E. Northington, M.D. Pacheco, D.G. Rickel, E.L. Robinson, J.D. Rogers, J.B. Schillig, J.R. Sims

SUBMITTED TO: Thirteenth International Conference on Magnet Technology

\section{DISCLAIMER}

This report was prepared as an account of work sponsored by an agency of the United States Government. Neither the United States Government nor any agency thureof, nor any of their employees, makes any warranty, express or implied, or assumes any legal liability or responsibility for the accuracy, completeness, or usefulness of any information, apparatus, product, or process disclosed, or represents that its use would not infringe privately owned rights. Reference herein to any specific commercial product, process, or service by trade name, trademark, manufacturer, or otherwise does not necessarily constitute or imply its endorsement, recom. mendation, or favoring by the United States Government or any agency thereof. The views and opinions of authors expressed herein do not necessarily state or reflect those of the United States Government or any agency thereof. 


\title{
Prototype Tests and Description of a 60 Tesla Quasi- Continuous Magnet
}

\author{
J.R. Sims, T. Dominguez, T. E. Northington, M.D. Pacheco, D.G. Rickel, \\ E.L. Robinson, J.D. Rogers, J.B. Schillig \\ National High Magnetic Field Laboratory, Los Alamos National Laboratory \\ Los Alamos, New Mexico 87545
}

\begin{abstract}
The National High Magnetic Fleld Laboratory has designed and will bulld a large bore, 60 tesia, $100 \mathrm{~ms}$ (quasi continuous) flat-top magnet for Installation and use at Los Alamos. The magnet consists of elght concentric, resistive, solenoid colls fabricated from high strength, high conductlvity copper supported by external stainless steel shells. Before each pulse the magnet is cooled to $77 \mathrm{~K}$ with liquld nitrogen. The energy for the magnet is provided through converter power supplies from a $1430 \mathrm{MVA}, 24 \mathrm{kV}$ alternating current energy storage generator. Plans for prototype tests of full scale portions of the magnet are discussed. A detalled description of the magnet is presented along with avallable Information on fabrication methods to be employed in its manufacture.
\end{abstract}

\section{INTRODUCTTON}

The National High Magnetic Field Laboratory has made the commitment to make available to the high magnetic field research community a $33 \mathrm{~mm}$ bore pulsed solenoidal magnet that will produce a 60 tesla ficld for a $100 \mathrm{~ms}$ duration. Construction of such a magnet using presently available materials presents a challanging task. The large bore creates stress management problems and the long duration causes heat management problems. Containment of the stress requires high strength conductois and a complex design of several nested coils with extemal reinforcement shells around each of the interior coils. Management of the thermal loading requires the conductors to have high electrical conductivity enhanced by liquid nitrogen cooling. The magnet design is a result of extensive materials research, analytical computations and optimization, and finally finite element analysis of the coil structures with realistic loading.

A set of prototype coils are designed and are to be manufactured and tested to verify manufacturing techniques and the structural analysis, to determine operating envelope and the electrical integrity of the design.

\section{Il. Magnet Description}

The 60 tesla-100 ms pulsed magnet is constructed from eight mechanically independent, concentric, nested, resistive, solenoid coils (see Fig. 1). The inner seven coils have external stainless stecl reinforcing shells. The cight coils

Manuscript received September 20, 1993. This work supported by National High Magnetic Ficld Latoratory and National Science Foundation, cooperative agreement No. DMR-9016241. with their leads and busbar are supported with their longitudinal axes vertical, in a fiberglass epoxy laminate and stainless steel frame. The frame is mounted within a stainless steel dewar vessel. To meet schedule and reliability requirements magnet materials were selected from characterized, commercial materials available from dependable sources of supply.
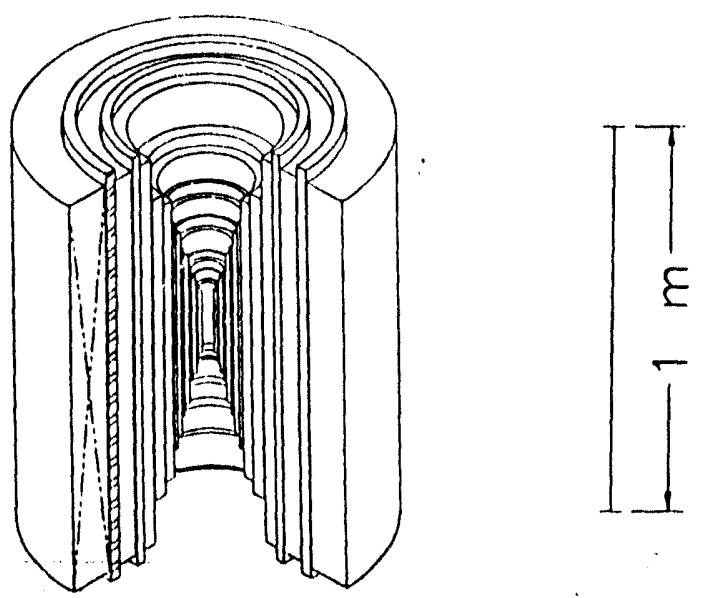

Fig. 1. Isometric drawing of the 60 tesla magnet showing the coils and the shells

Individual coils are constructed from drawn aluminum oxide dispersion strengthened copper conductors insulated with E-glass fabric tape and cloth combined with polyimide film tape (Fig. 2). The coils are formed by winding the tape insulated conductor about a mandrel, inserting the wound coil

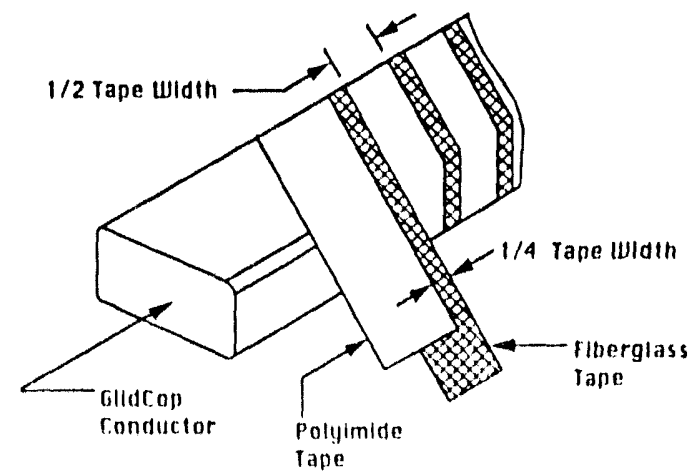

Fig. 2. Insulation wrapping about conductor. Insulation is applied as the magnet is wound. 
into the external supporting shell and then vacuum impregnating the coil with cryogenic rated, anhydride cured, epoxy resin.

The external supporting shells are constructed from nitrogen-alloyed manganese stainless steel (Fe-21 Cr-6Ni$9 \mathrm{Mn})$. The shells, by their stiffness and strength, reinforce the coils by carrying a significant portion of the radial and axial loads produced by magnetic forces [1]. The large elongation and high ultimate tensile strength of the shells provide containment in the event of a coil failure.

Coil leads are arranged at one end of the coil, in an interlocking manner, as shown in Fig. 3, to allow the hoop loads from the end turns and loads from the leads to react against each other. This design channels the loads directly into the high strength conductor and external supporting shell without depending upon the shear strength of the electrical insulation system on the end turns. Leads from each coil are paired together and project axially from the coil. The leads are heavily insulated, bound together with high strength $\mathrm{S}-2^{*}$ glass roving and impregnated with the coil. A provision for a brazed field splice to the busbar system is included at the lead end. Coil conductors and leads are supported by epoxy fiberglass laminate filler pieces or other conductors throughout the coil. Cross-overs between layers at coil ends are fully supported by filler pieces and when required incorporate space for brazed conductor splices.

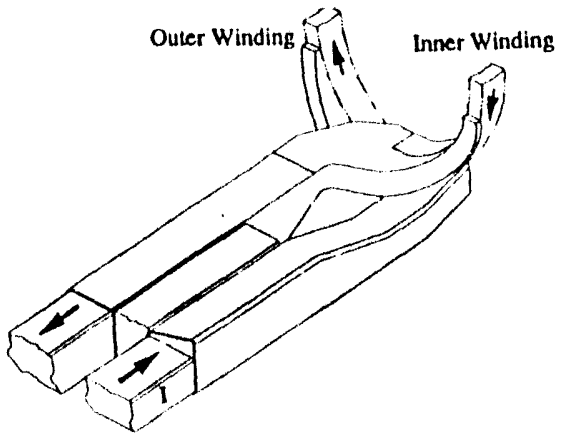

Fig. 3 . End on view of coil 1 showing the coil leads projecting out of the figure.

The coil support frame consists of thick epoxy fiberglass laminate hubs and endplates (Fig. 4). These hubs and plates are axially joined using stainless steel tie rods. The coil support frame positions the individual coils and busbar system, supports gravity loads, absorbs magnetic loads from the busbar and coil magnetic misalignment and provides a means of channeling liquid nitrogen for cooling between the coils. Mounting and fastening in the frame accommodate thermal expansion and magnetic misalignment. The frame provides a means of lifting a coil or coils from the dewar. Containment in the event of coil failure is also provided by the frame.

The coil dewar is fabricated from non-magnetic stainless stecl. It supports the gravity loads of the magnet frame, reduces the external thermal load on the magnet and experimental apparatus and contains the liquid nitrogen and nitrogen gas used to cool the magnet. The dewar contains an optical window at its base. The head or top of the dewar

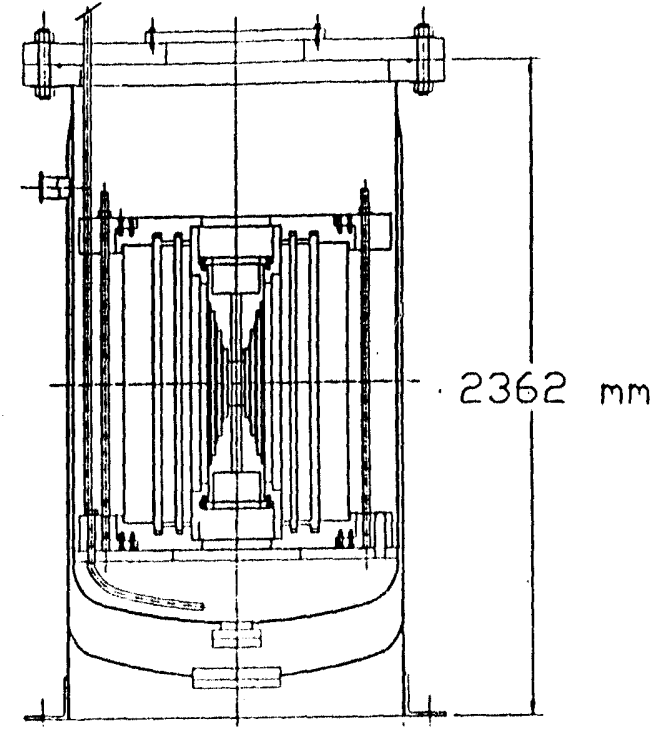

Fig. 4. Cross sectional drawing of magnet showing coil frame and dewar.

incorporates fittings and provisions for the mounting of experiments, the attachment of electrical power and liquid nitrogen feedthroughs and venting of nitrogen gas.

\section{Prototype Tests}

\section{The power supply}

A simulation of the exact stresses in the prototype coils can not practically be devised because of the lack of a full coil set. We selected the 2 inner coils for the prototype test because they are the least expensive coils to manufacture and have most of the design features of the rest of the coils. To stress the coils near the actual operating conditions requires higher current densities than the full coil system because of the lack of external fields produced by the remaining coils. Such a current overdrive changes the stress distribution in the prototype coils but will still permit us to compare our finite element model predictions against actual performance.

We will use a $22 \mathrm{mf}, 10 \mathrm{kV}$ capacitor bank as a current drive for the prototype tests. The two coils will be nested and connected in series. The circuit response has been calculated, see Fig. 5. With a capacitor charge voltage of $4 \mathrm{kV}$, the discharge cycle will produce a peak current of $54 \mathrm{kA}$ with a half-period of $4 \mathrm{~ms}$. This current level is estimated to produce the correct radial loading on the shells of the coils. A finite element calculation, which models the structural response of the coil and support shell, will be necessary to predict the actual current necessary to produce the desired coil and shell loading.

\footnotetext{
* S-2 glass is a trademark of Owens Corning Fiberglass Corp.
} 


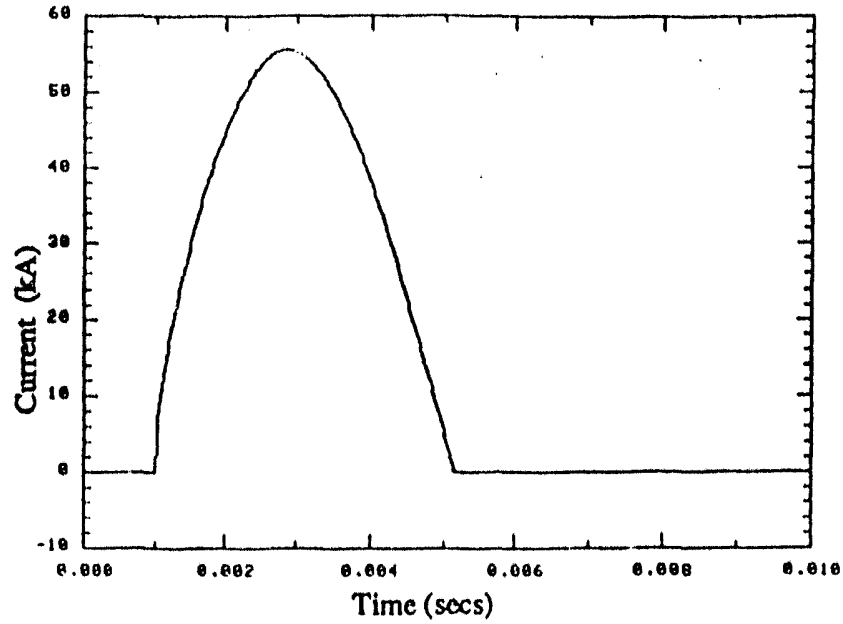

Fig. 5. Current waveform produced by the capacitor bank discharge into the coil 1 and coil 2 prototypes

\section{The Diagnostics}

Strain measurements are the most desirable data from the tests. The external surface of the coil shells will be instrumented with an array of strain gauges and strains will be measured before and after coil excitations. We also will try to instrument some strain gauges so that we can acquire the dynamic response of the coil and the support shell. This may be difficult because of the changing magnet flux present at the strain gauge locations. We have had success in making four terminal measurements in the presence of large $\mathrm{dB} / \mathrm{dt}$ by using the AC phase sensitive detection technique. Such a technique, however, will only permit us to make relative strain measurements because AC excitation of the strain gauges will have an associated skin effect.

\section{REFERENCES}

[1] L. M. Lontai and P. G. Marston, "A 100 kilogauss quasicontinuous cryogenic solenoid - Part I," Proc. Intern. Symp. Magnet Technology, 723. Standford, 1965.

\section{DISCLAIMER}

This report was prepared as an account of work sponsored by an agency of the United States Government. Neither the United States Government nor any agency thureof, nor any of their employees, makes any warranty, express or implied, or assumes any legal liability or responsibility for the accuracy, completeness, or usefulness of any information, apparatus, product, or process disclosed, or represents that its use would not infringe privately owned rights. Reforence herein to any specific commercial product, process, or service by trade name, trademark, manufacturer, or otherwise does not necessarily constitute or imply its endorsement, recommendation, or favoring by the United States Government or any agency thereof. The views and opinions of authors expressed herein do not necessarily state or reflect those of the United States Government or any agency thereof. 

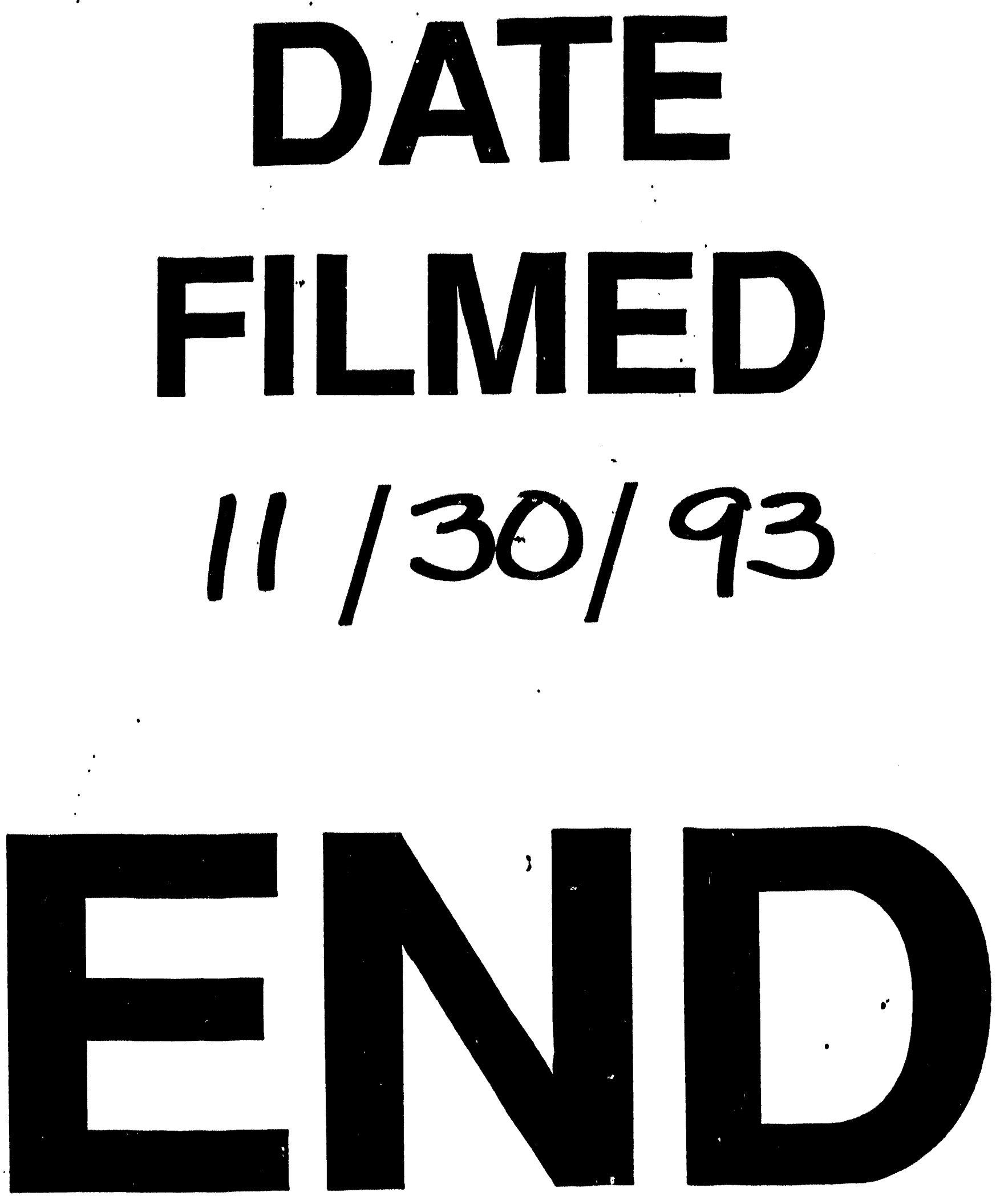
